\title{
INVESTIGANDO AÇÕES EM EDUCAÇÃO AMBIENTAL: O PROGRAMA AGRINHO E AS HISTÓRIAS DE VIDA DE SEUS EX- ALUNOS
}

\author{
Antonio José Radi ${ }^{1}$ \\ Cleverson Vitorio Andreoli ${ }^{2}$ \\ Valdir Fernandes ${ }^{3}$
}

Resumo: O Agrinho é um programa educacional organizado e conduzido pelo Serviço Nacional de Aprendizagem Rural/Paraná, cujas atividades tiveram início no ano de 1996. O presente trabalho tem como objetivo caracterizar e identificar as contribuições do Programa Agrinho em suas ações voltadas para a educação ambiental. Esta pesquisa é de natureza qualitativa e como instrumentos de coleta de dados foram utilizados a História de Vida e entrevistas semiestruturadas. Para atender aos objetivos propostos foram feitas entrevistas com ex-alunos maiores de 18 anos. O modelo de análise baseouse na construção de categorias e nos pressupostos da educação ambiental crítica. As narrativas revelaram que os jovens tiveram um contato bastante breve com o programa ao longo da vida estudantil, daí a razão de serem poucas as lembranças relacionadas ao Agrinho. No que tange aos assuntos ligados ao meio ambiente, os ex-alunos demonstraram estar cientes da gravidade da questão ao mesmo tempo em que relacionaram os problemas ambientais às ações antrópicas.

Palavras-chave: Meio ambiente. Educação ambiental. Programa Agrinho.

\section{INVESTIGATING ACTIONS IN ENVIRONMENTAL EDUCATION: AGRINHO PROGRAM AND THE LIFE STORIES OF ITS FORMER STUDENTS}

Abstract: Agrinho is an educational program organized and conducted by the National Rural Apprenticeship Service/Paraná (SENAR-PR) whose activities began in 1996. This study aims at characterizing and identifying the contributions of the Agrinho Program in its actions towards environmental education. This research work is qualitative and its tools of data generation are composed of life history and semi structured interviews. In order to achieve the proposed objectives interviews were done with former students older than 18 years old. The model of analysis was based on the construction of categories and on the assumptions of critical environmental education. The narratives revealed that the students interviewed had a brief contact with the program throughout their student lives, reason for their few memories related to Agrinho. Concerning the subjects related

\footnotetext{
1 Engenheiro Agrônomo, Mestre em Organizações e Desenvolvimento pela FAE, Londrina, Paraná, Brasil, universitárioajoradi@gmail.com

2 Engenheiro Agrônomo, Mestre em Ciências do solo pela Universidade Federal do Paraná, Doutor em Meio Ambiente e Desenvolvimento pela Universidade Federal do Paraná. Professor titular da FAE - Centro Universitário, Londrina, Paraná, Brasil, c.andreoli@sanepar.com.br

${ }^{3}$ Sociólogo, Mestre em Engenharia Ambiental pela Universidade Federal de Santa Catarina, Doutor em Engenharia Ambiental pela Universidade Federal de Santa Catarina (UFSC), Santa Catarina, Brasil, valdir.fernandes@icloud.com
} 
to the environment, the youngsters revealed being aware of the seriousness of the issue as well as related the environmental problems to human actions.

Keywords: Environment. Environmental Education. Agrinho Program.

\section{INVESTIGANDO ACCIONES EN EDUCACIÓN AMBIENTAL: EL PROGRAMA AGRINHOY LAS HISTORIAS DE VIDA DE SUS EX ALUMNOS}

Resumen: El Agrinho es un programa educacional organizado y dirigido por el Servicio Nacional de Aprendizaje Rural/Paraná, cuyas actividades tuvieron inicio el año de 1996. El presente trabajo tiene como objetivo caracterizar e identificar las contribuciones del Programa Agrinho en sus acciones dirigidas a la educación ambiental. Esta investigación es de naturaleza cualitativa y como instrumentos de recogida de datos se utilizaron la Historia de Vida y entrevistas semiestructuradas. Para atender los objetivos propuestos se hicieron entrevistas con ex alumnos mayores de 18 años. El modelo de análisis se basó en la construcción de categorías y en los presupuestos de la educación ambiental crítica. Las narrativas revelaron que los jóvenes tuvieron un contacto bastante breve con el programa a lo largo de la vida estudantil, de ahí la razón de ser pocos los recuerdos relacionados al Agrinho. En lo que se refiere a los asuntos relacionados al medio ambiente, los ex alumnos demostraron estar conscientes de la gravedad de la cuestión, al mismo tiempo en que relacionaron los problemas ambientales a las acciones antrópicas.

Palabras clave: Medio ambiente. Educación ambiental. Programa Agrinho.

\section{Introdução}

Ao se pensar a educação como um processo, aspectos como a longevidade e a continuidade assumem grande importância aos olhos do pesquisador que se lança no trabalho investigativo de um programa de educação ambiental. Organizado e conduzido pelo Serviço Nacional de Aprendizagem Rural/Paraná (SENAR-PR) e em atividade ininterrupta há 17 anos, o Agrinho apresenta-se como um programa educacional com história e presença em muitas escolas públicas - e também em algumas escolas privadas - do Estado.

O SENAR-PR faz parte do Sistema FAEP (Federação da Agricultura do Estado do Paraná); foi criado pela Lei Federal n. 8315 de 23 de dezembro de 1991 (BRASIL, 1991) e regulamentado pelo Decreto n. 566/92 de 10 de Junho de 1992 (BRASIL, 1992). O objetivo do SENAR é promover a capacitação profissional e a promoção social do trabalhador rural e suas diretrizes de ação são:

- atingir a grande massa de trabalhadores rurais;

- priorizar a qualificação dos que se encontram em estágios mais atrasados em cada segmento;

mobilizar todo o potencial da sociedade organizada tais como: sindicatos, cooperativas estabelecimentos de ensino e pesquisa, fabricantes e distribuidores de insumos, máquinas e equipamentos, órgãos do Governo e entidades privadas, estabelecendo acordos de cooperação para trabalhos conjuntos; 
- maximizar os resultados dos recursos financeiros disponíveis, procurando utilizá-los em um modelo de gestão de baixos custos fixos, privilegiando as atividades fins;

- ações de formação profissional modulares, com alta capilaridade, propiciando igualdade de oportunidades;

- combinar qualificação com promoção social, de forma a orientar o trabalhador/produtor a tirar o melhor proveito econômico e social de seu trabalho e/ou de sua propriedade.

No âmbito da dimensão de promoção social do SENAR, foi proposto, em 1995, o Programa Agrinho, que entrou em prática em 1996.

As primeiras ações do programa focaram a saúde do trabalhador rural e de sua família, uma vez que, naquela época, eram alarmantes os casos de intoxicação por agrotóxicos no Estado do Paraná, bem como os casos de contaminação do meio ambiente pelo uso e descarte indevidos de agrotóxicos. Essa abordagem sofreu uma profunda mudança a partir de 1998, quando o foco dos conteúdos passou a ser a agricultura equilibrada, considerando a sua relação com o solo, o clima, a água e a biodiversidade.

O público-alvo das ações educativas do Agrinho foi, desde o início, crianças em idade escolar. Dessa forma, buscava-se, desde a tenra idade, conscientizar os jovens a respeito dos riscos e malefícios relativos ao uso indevido de produtos químicos - tanto para as pessoas quanto para a natureza - atendendo-se, assim, conforme salientam Torres e Cervi (2001, p.13), [...] a "uma recomendação constante na Agenda 21/1992/ONU".

Em sua implantação, o Programa Agrinho recrutou especialistas que proferiram palestras para professores da primeira à quarta série do Ensino Fundamental. Para apoio às ações dos docentes, o SENAR-PR elaborou materiais didáticos específicos para o Agrinho (TORRES; CERVI, 2001).

Agindo assim, as atividades educativas cumpriam um duplo propósito: prevenir acidentes com os menores de idade e incentivar a influência destes junto aos pais e familiares (TORRES; CERVI, 2001). Interessante mencionar que, embora priorize a escola pública, a partir de 2007 algumas escolas particulares também passaram a adotar o material didático e as práticas previstas no Programa Agrinho.

Todo o material didático do Programa é distribuído gratuitamente, tanto para escolas públicas como para escolas privadas. Para as primeiras, o material é enviado automaticamente, sem haver necessidade de solicitação por parte da instituição de ensino. Já as escolas privadas que desejarem receber o material devem solicitá-lo. A utilização do material didático do Programa Agrinho é sempre voluntária, cabendo ao docente optar ou não pela sua adoção paralelamente à grade curricular formal. A última reformulação dos livros em uso ocorreu em 2007.

O Programa Agrinho conta com várias parcerias públicas e privadas; entre os órgãos governamentais estão o Ministério Público, Prefeituras Municipais e Secretarias de Estado do Governo do Paraná, o Ministério do Trabalho e Emprego, a Receita Federal, o Ministério Público do Trabalho e a Previdência Social.

Pelo seu relativamente longo tempo de existência, o Programa Agrinho revela-se como uma diversificada e abundante fonte de informações, estimuladora de estudos e pesquisas que podem direcionar-se tanto para os conteúdos do programa como para o público participante das atividades pedagógicas por ele promovidas.

Os idealizadores do Programa preocupam-se, constantemente, com a avaliação do Agrinho por parte do público participante. Para tanto, anualmente são organizados concursos estaduais que, hoje, premiam cinco categorias: Desenho, Redação, Experiência Pedagógica, Escola Agrinho e Município Agrinho. Os prêmios vão desde TVs, bicicletas até automóveis zero $\mathrm{km}$.

A evolução quantitativa do Programa Agrinho, ao longo dos seus 16 anos de existência, é considerável: em 1996, participaram das ações do Programa 7.443 alunos de 05 municípios 
paranaenses; em 2012, 1.028.275 revistas foram disponibilizadas a alunos do ensino fundamental público - primeiro ao nono ano - em 329 municípios. Quanto às escolas privadas, o montante chegou a 16.311 revistas distribuídas em 93 municípios.

O grande avanço, porém, não se restringiu ao número de participantes do Programa; as temáticas abordadas também se expandiram sobremaneira, estando, hoje, inseridas em sete temas transversais: Ética, Meio Ambiente, Saúde, Cidadania, Pluralidade Cultural, Orientação Sexual, Temas Locais e Trabalho e Consumo. O tema Meio Ambiente, por sua vez, subdivide-se nas temáticas: Solo, Água, Agrotóxico, Mudanças Climáticas, Biodiversidade e Desenvolvimento Sustentável.

Em sua proposta pedagógica, o Programa Agrinho fundamenta-se na Pedagogia da Pesquisa, metodologia esta que prima pela interdisciplinaridade e pela transversalidade, propondo uma "educação crítica, criativa, reflexiva que desenvolva em docentes e discentes a inventividade, a autonomia e o comprometimento, tornando-os sujeitos pesquisadores fazedores da História atual, capazes de produzir novos conhecimentos" (TORRES, 2007, p. 10).

Diante de uma evolução e de um tempo de existência quantitativamente tão significativos, surgiu o objetivo geral da presente pesquisa: identificar as contribuições oriundas das ações de educação ambiental do Programa Agrinho.

Dentre os objetivos específicos estabelecidos, dois são abordados no presente artigo: 1) estabelecer a relevância de assuntos relacionados ao meio ambiente na vida de alunos que tiveram contato com o Programa Agrinho e 2) identificar o papel da educação nos projetos de vida de exalunos do Agrinho. Para tanto, este estudo colheu a narrativa de ex-alunos - hoje maiores de 18 anos - participantes do Agrinho.

\section{Metodologia}

Visando atingir os objetivos propostos, o presente trabalho fez opção pela pesquisa qualitativa.

Segundo Paulilo (1999) a investigação qualitativa aplica-se a estudos cujos objetos são complexos e de difícil apreensão e compreensão tais como valores, hábitos, representações, opiniões.

Minayo e Sanches (1993) preconizam que uma análise qualitativa deve transcender a mensagem verbalizada para mergulhar em seus significados não manifestos.

Para colher as narrativas de ex-alunos que tiveram contato com o Programa Agrinho fezse necessária não apenas a aproximação junto a essas pessoas, mas também, e principalmente, a utilização de ferramentas que possibilitassem a apreensão dos pontos de vista desses indivíduos. Para atender a essa necessidade, optou-se pela história de vida e pela utilização de entrevistas semiestruturadas.

De acordo com Marconi e Lakatos (2008) a narrativa de história de vida gira em torno de acontecimentos, os quais são influenciados pelo contexto sociocultural do entrevistado.

Bogdan e Biklen (1994) enxergam na história de vida uma busca pela reconstrução da trajetória do indivíduo, onde episódios e pessoas marcantes são evidenciados na formação do caráter e dos anseios do entrevistado.

Paulilo (1999) ressalta que a história de vida possibilita a interseção de fatos passados com eventos presentes, o que culmina na visão ampliada e na compreensão aprofundada da vida dos narradores.

Fica evidente, portanto, que a História de Vida enfatiza o ponto de vista das pessoas entrevistadas; são os sujeitos-informantes da pesquisa e suas narrativas que conduzem as ações do sujeito-pesquisador.

Martins e Theóphilo (2007) caracterizam entrevista semiestruturada como aquela que se utiliza de um roteiro previamente elaborado, porém com abertura para a adição de novos questionamentos por parte do entrevistador. 
Gil (2008) recomenda que o entrevistador mantenha o foco, ouça muito, fale pouco e estimule o entrevistado a dar respostas relevantes em relação ao tema da pesquisa.

Nas narrativas dos ex-alunos que participaram das fases iniciais do Programa, a leitura das transcrições tentou, em um primeiro momento, identificar a emergência espontânea de quaisquer assuntos relacionados à temática ambiental. Em um segundo momento, os ex-alunos foram questionados a respeito de seus projetos de vida e sobre três temas ambientais recorrentes no material didático do Agrinho: Água, Clima e Biodiversidade. A partir das respostas desses jovens, foram construídos conjuntos de categorias específicas para cada um dos temas mencionados.

De acordo com Gomes (1994), uma vez estabelecidas, as categorias específicas devem ser articuladas às categorias gerais definidas antes da coleta de dados. Assim, esta pesquisa analisou os dados coletados fundamentando-se na abordagem crítica e emancipatória da Educação Ambiental.

A análise do conteúdo das entrevistas realizadas com um grupo de cinco ex-alunos procurou caracterizar o Agrinho nos primeiros anos de funcionamento do Programa. Simultaneamente, buscou-se resgatar as lembranças do contato e das atividades realizadas, bem como verificar se e como emerge a temática ambiental na vida desses jovens. Foi feita, também, uma sondagem a respeito do conhecimento dessas pessoas com relação a temas ambientais de grande destaque na atualidade, temas estes presentes no material didático do Programa Agrinho. Os jovens tiveram suas histórias de vida gravadas e, posteriormente, transcritas.

\section{Fundamentos para uma educação transformadora}

Nos dias de hoje, ser bem sucedido ou vencer na vida são expressões que, invariavelmente, levam a pensar que aquela pessoa, vencedora e bem sucedida, alcançou notoriedade e/ou acumulou significativa quantidade de bens materiais. Essa moderna concepção de sucesso é construída historicamente e reflete as crenças e valores predominantes em uma sociedade.

Para Marín (2007) esse processo de jugo econômico, perpetrado pelo ocidente, teve início com as Cruzadas para expandir-se, posteriormente, para a África e Américas com o advento das grandes navegações. Assim, gradativamente, uma nova racionalidade consolidou-se, pautada em fatores econômicos e mercadológicos e tendo como características o reducionismo e o cientificismo (LEFF, 2006; SAUVÉ, 2005).

Inserida nesse contexto, a educação, enquanto prática social sofre grande influência dos interesses políticos e econômicos dominantes. Mais do que isso, pode-se mesmo dizer que a educação, frequentemente, atua de forma a sedimentar e perpetuar as relações vigentes em nossa sociedade.

Para Paoli (1981), a cumplicidade entre modo de produção e educação tem início com a segmentação e a especialização do trabalho. Segundo o autor, a compartimentalização das operações fabris, onde cada operário atua somente em uma determinada etapa do processo de produção, demandou a qualificação do trabalhador, abrindo espaço para a graduação das atividades produtivas. A mão de obra passou, então, a ser valorada de acordo com a complexidade do trabalho executado.

Esse fenômeno apresenta uma consequência bastante visível em nossa sociedade; ele legitima uma desigualdade social baseada nos anos de estudos de um profissional. Assim, passa a ser natural e desejável que um profissional com curso superior receba significativamente mais que outro profissional que não teve capacidade - ou condições - de concluir o ensino fundamental. Nesse contexto, a qualificação profissional torna-se apenas um meio para se alcançar um fim: a busca por colocação no mercado e/ou por maiores salários.

É de se esperar, no entanto, que um sistema econômico marcado pela desigualdade imponha barreiras ao crescimento profissional de muitos cidadãos. Sob esse aspecto, Paoli (1981) salienta que a escola possui um importante papel limitador à medida que restringi o acesso das pessoas seja por fatores financeiros, burocráticos ou motivacionais. 
Ainda segundo o autor, o sistema educacional brasileiro contribui para a desigualdade social à medida que difunde o saber de forma diferenciada. Além disso, ao preparar cidadãos para o mercado, prioriza o individual em detrimento do coletivo, desestimulando a autonomia, a criatividade e o senso crítico dos educandos.

Esse lado elitista do ensino também é visualizado por Brandão (2007). Para o autor, o conhecimento alia-se à dominação para a manutenção do status quo de uma minoria.

Para Freire (2003), criticidade, liberdade e democracia são valores intimamente relacionados entre si. Sociedades carentes dessa tríade, como a nossa, tendem a tratar seus problemas de forma fragmentada e pouco aprofundada: "Esta nos parecia uma das grandes características de nossa educação. A de vir enfatizando cada vez mais em nós posições ingênuas, que nos deixam sempre na periferia de tudo o que tratamos" (FREIRE, 2003, p. 103-104).

Diante de um quadro tão desalentador, revelando uma educação tão transfigurada, cúmplice de um sistema econômico socialmente injusto e ambientalmente predatório, caberia questionar se ainda há espaço para o desenvolvimento de outro modelo de educação.

A resposta a esse questionamento começa a ser fornecida por Brandão (2007), quando o autor faz recordar que a educação é maior que os sistemas econômicos e que o criador (homem) é maior que a criatura (educação). Muito apropriadamente, o autor faz menção ao caráter dialético da educação: enquanto formadora de homens é também por eles formada; enquanto alienadora é também emancipadora; enquanto aprisionadora, é também libertadora.

Freire confronta duas concepções de educação: a educação bancária e a educação problematizadora. Um modelo de educação bancária vislumbra os educandos como sujeitos passivos, acríticos, apáticos, incapazes de pensar por si mesmos e de interagir ao longo do processo educativo: “[...] desta maneira, a educação se torna um ato de depositar, em que os educandos sãos os depositários e o educador o depositante" (FREIRE, 2005, p. 66). Nessa concepção de educação enfatiza-se a adaptação dos sujeitos a uma realidade posta e imutável.

$\mathrm{Na}$ educação problematizadora, por sua vez, Freire (2005) propõe a superação da relação dicotômica entre educador e educando: "Desta maneira, o educador já não é o que apenas educa, mas o que, enquanto educa, é educado, em diálogo com o educando que, ao ser educado, também educa" (FREIRE, 2005, p. 79). Esta relação dialógica, reflexiva e crítica desvela uma realidade dinâmica, repleta de interações e em constante transformação.

Assim, sob essa ótica, o mundo está em constante construção e, portanto, toda realidade é passível de intervenção e transformação: "Não sou apenas objeto da História mas seu sujeito igualmente. No mundo da História, da cultura, da política, constato não para me adaptar mas para mudar' (FREIRE, 1996, p.77, grifo nosso).

Embora vários cenários vislumbrem a possibilidade de uma catástrofe ambiental e de um consequente colapso civilizacional (DIAMOND, 2005; JACOBI, 2005; JONAS, 2006), pensadores como Freire $(1996,2005)$ demonstram que a educação - alicerçada sobre outros saberes e outros princípios - pode transformar o presente e redesenhar o futuro. Essa concepção de educação - crítica e transformadora - ao priorizar assuntos ambientais, deve, portanto, transcender o tema proteção da natureza e mergulhar em questões históricas, sociais, políticas e culturais.

Assim, a educação ambiental crítica preconiza a reflexão a respeito da problemática ambiental não apenas do ponto de vista biológico, mas, também, considerando aspectos sociais, econômicos, políticos e históricos de forma a propiciar condições para a intervenção e transformação da realidade circundante (LOUREIRO, 2009).

Quadro 1 - Concepções de educação ambiental

\begin{tabular}{|l|l|}
\hline Concepção reformista & \multicolumn{1}{|c|}{ Concepção transformadora } \\
\hline Concebe a sociedade como lugar da harmonia e & Concebe a sociedade como lugar dos conflitos e a \\
os conflitos como uma disfunção no seu & existência deles como inerente à dinâmica social. Os \\
funcionamento. Os problemas ambientais são & problemas ambientais são inerentes ao caráter não \\
causados por uma disfunção que dificulta & sustentável da atual ordem social. Portanto, não há \\
\hline
\end{tabular}




\begin{tabular}{|l|l|}
\hline $\begin{array}{l}\text { compatibilizar desenvolvimento e proteção ao } \\
\text { meio ambiente. }\end{array}$ & $\begin{array}{l}\text { possibilidade de compatibilização, mas apenas de } \\
\text { mitigação. }\end{array}$ \\
\hline $\begin{array}{l}\text { A crise é estritamente ambiental. Sua superação } \\
\text { dependerá da adoção de padrões de produção e } \\
\text { consumo que crise ambiental é a manifestação da crise de uma } \\
\text { desenvolvimento com proteção ambiental. E a a } \\
\text { sustentabilidade seria alcançada quando fosse } \\
\text { atingida a compatibilidade plena. }\end{array}$ & $\begin{array}{l}\text { determinada concepção de civilização. Sua superação } \\
\text { racionalidades que a produz. E a sustentabilidade } \\
\text { resultará do processo de construção coletiva de uma } \\
\text { nova ordem social, que seja justa, democrática e } \\
\text { ambientalmente responsável. }\end{array}$ \\
\hline $\begin{array}{l}\text { Prevenção e solução dos problemas ambientais } \\
\text { dependem de cada um fazer a sua parte. }\end{array}$ & $\begin{array}{l}\text { Cada um fazer a sua parte não garante a prevenção e a } \\
\text { solução dos problemas ambientais. Isso depende da } \\
\text { construção de consensos na sociedade, ou seja, de ação } \\
\text { política. }\end{array}$ \\
\hline Transformar-se para transformar. & Transformar-se transformando. \\
\hline Prática pedagógica prescritiva e reprodutiva. & $\begin{array}{l}\text { Prática pedagógica crítica, transformadora e } \\
\text { emancipatória. }\end{array}$ \\
\hline
\end{tabular}

FONTE: Quintas (2009)

\section{As entrevistas com ex-alunos}

Ex-alunos participantes do Programa Agrinho narraram suas Histórias de Vida, abordando acontecimentos e experiências vivenciadas na infância, na adolescência e na fase adulta. Todos os ex-alunos participaram do Programa Agrinho quando eram crianças; suas participações tiveram duração de algumas semanas (Categoria Redação) ou de um ano letivo (Experiência Pedagógica).

$\mathrm{Na}$ primeira parte da entrevista, buscou-se identificar a emergência espontânea de quaisquer assuntos relacionados ao meio ambiente. Nenhum dos ex-alunos entrevistados, no entanto, trouxe à tona a temática ambiental durante a narrativa. Na segunda parte da entrevista, os ex-alunos foram questionados a respeito de seus projetos de vida e sobre três temas presentes no material didático do Programa Agrinho: Água, Clima e Biodiversidade.

\subsection{Tema: Água}

Quando indagados a respeito da ameaça de escassez de água no Brasil, os jovens, de um modo geral, demonstraram preocupação e até mesmo pessimismo em relação ao futuro:

Segmento 1:

Al.2: Do jeito que está indo uma hora vai acabar, né?

Segmento 2:

Al.1: Tem que começar, não digo racionar, mas, digamos, economizar bastante já, desde já, porque preocupa.

Segmento 3:

Al.4: É uma coisa que a gente tem em abundância, mas é uma coisa que a gente sabe que um dia vai acabar. Não é para sempre, não é uma coisa eterna.

Segmento 4:

Al.3: A água não vai faltar, mas a potável, boa para consumo, eu acho que vai faltar sim. Segmento 5:

Al.5: (...) ela é abundante (...). É muito mal explorada e... e muito mal utilizada também.

Interessante observar nas narrativas expostas que Al.2 e Al.4 transmitem a ideia de água como um recurso finito e não como um elemento em permanente ciclo em nosso planeta. Al.3, por sua vez, refere-se à falta de água apropriada para consumo e não da água em si. Al.5 sugere o uso mais eficiente desse recurso.

Outra constatação, a partir dos extratos acima, é a de que, na visão dos jovens, a escassez de água será ou poderá vir a ser uma ameaça; ou seja, não é um problema no presente, pelo menos no Brasil. A leitura da Pesquisa Nacional de Saneamento Básico 2008, publicada pelo IBGE, demonstra uma realidade diferente. Ao abordar a ocorrência de racionamento de água em 
cidades da região Nordeste naquele ano, o relatório revela números alarmantes em Estados como Pernambuco, Ceará e Rio Grande do Norte os quais tiveram, respectivamente, 77,3\%, 48,9\% e $46,7 \%$ de seus municípios afetados por racionamentos (IBGE, 2010).

Sob a ótica desses dados, o problema de escassez de água no Brasil é atualíssimo; não obstante, essa triste e crônica realidade nacional passou despercebida pelos jovens. Sendo um fato amplamente divulgado pela mídia, é pouco provável que esses ex-alunos ignorem o drama da seca no nordeste brasileiro; assim, parece ser mais adequado imaginar que esses moços e moças encontrem-se arrebatados por uma realidade mais imediata, visível, próxima e, também, limitada. No que concerne às possíveis soluções para se evitar a falta de água, as narrativas revelaram dois conjuntos de categorias:

- Comportamentais: poupar, reutilizar, racionar, conscientizar.

- Tecnológicas: dessalinização de águas oceânicas, tratamento de esgoto, utilização de águas subterrâneas e gestão dos recursos hídricos.

As alternativas ditas comportamentais são bastante difundidas nos meios de comunicação e parecem já ter se incorporado no imaginário de muitos cidadãos. O poupar e o reutilizar para os ex-alunos referem-se a ações como não deixar a torneira aberta, tomar banho rapidamente, não lavar a calçada diariamente, reaproveitar a água da máquina de lavar roupa. O conscientizar refere-se ao lançamento de campanhas para esclarecimento popular. Na sequência, quando questionados sobre o segmento de maior demanda de água, a maioria dos ex-alunos apontou o abastecimento urbano. Essa informação já se encontrava presente no material do professor do ano 1999-2002, onde o consumo doméstico, em nível mundial, representava apenas 4\% do total. No material do professor de 2007-12, o dado aparece também nacionalmente, ficando o abastecimento urbano com $8 \%$, o setor industrial com $20 \%$ e a agricultura com $70 \%$ da demanda total. Assim, embora sejam pertinentes, as soluções comportamentais têm impacto apenas sobre o segmento (abastecimento urbano) responsável pela menor utilização de água.

Quanto às soluções tecnológicas, o tratamento de esgotos e uma eficiente gestão dos recursos hídricos contribuem sobremaneira para evitar, respectivamente, a poluição e o desperdício de água. A exploração de águas subterrâneas, conduzida de forma criteriosa, pode também revelar-se interessante diante das reservas existentes em nosso país. Em relação ao tratamento de água do mar para consumo humano, é sabido que há tecnologia para esse procedimento; porém, provavelmente sua viabilidade ficará restrita às regiões costeiras.

\subsection{Tema: Clima}

Em relação a esse tema, as perguntas objetivaram avaliar o entendimento dos jovens em relação às mudanças climáticas. Todos os entrevistados atribuíram as alterações do clima às ações antrópicas:

Segmento 6:

Al.2: O desmatamento, a poluição, tudo o que a gente está fazendo é, poluição de carros, indústrias, tudo o que a gente está fazendo hoje vai se refletir amanhã...

Segmento 7:

Al.1: Muitas indústrias não estão nem aí com o meio ambiente, joga resíduo e fumaça e muitos carros por aí... aumentou muito, né, a frota de carro no Brasil.

Segmento 8:

Al.4: O homem eu acho que ele contribui muito para isso. Um pouco é a Natureza se revoltando contra a gente.

Segmento 9:

Al.3: Indústria, poluição de carros, poluição diversas, até panela de pressão polui, né ((risos))?

Segmento 10:

Al.5: Porque, é... empresas produzem, o povo está consumindo, o poder aquisitivo no Brasil aumentou mais ainda, como não tacar gás na atmosfera que entre em contato com o ozônio, assim, vai degradando. 
As respostas possibilitaram identificar três categorias relacionadas às causas das Mudanças Climáticas: poluição industrial, desmatamento, destruição da camada de ozônio. As mudanças climáticas sempre foram relacionadas pelos ex-alunos à elevação média da temperatura do planeta; todavia, nenhum estudante mencionou o mais polêmico gás causador do efeito estufa: o dióxido de carbono. Mesmo as menções feitas à camada de ozônio - e sua relação com o aquecimento global - foram um tanto quanto confusas:

Segmento 11:

Al.3: Que eu me lembre é da camada de ozônio, que a poluição está acabando, o sol está entrando dentro da terra... estudei tanto isso só que não lembro muito.

Segmento 12:

Al.4: Não sou muito entendida nisso. Mas eu sei, por exemplo, que se queimar um pneu afeta, é... o nosso ecossistema, digamos assim, a atmosfera. Então... por exemplo, o aquecimento global está fazendo um buraquinho na camada de ozônio, na terra, e está entrando os ultravioleta que queimam, que machucam, que dá câncer de pele, para nós é muito ruim isso.

Quando indagados a respeito das ações objetivando combater as mudanças climáticas, dois jovens não souberam responder; as respostas dos demais possibilitaram a elaboração de dois conjuntos de categorias:

- Comportamentais: maior utilização do transporte coletivo, cada um fazer a sua parte.

- Tecnológicas: máquinas metabolizadoras dos gases atmosféricos, desenvolvimento de indústrias menos poluentes, despoluição.

O uso mais intenso do transporte coletivo poderia trazer algum alívio para o engarrafado trânsito das grandes cidades; porém, em um mundo onde $80 \%$ da energia elétrica é obtida através da queima de combustíveis fósseis (CNI, 2007), andar mais de ônibus, por si só, não parece ser uma solução de impacto significativo para a redução das emissões de dióxido de carbono. Quanto a cada um faz̧er a sua parte, a sentença remete a ações individualizadas e desconexas que pouco ou nenhum impacto possuem na solução dos problemas ambientais (QUINTAS, 2009).

Em relação às soluções tecnológicas apresentadas, máquinas capazes de retirar do ar e tornar inócuo o dióxido de carbono pode soar, a princípio, como algo factível. Há de se ter em mente, no entanto, que somente no ano de 2007, a queima de combustíveis fósseis no mundo gerou uma emissão de CO2 da ordem de 8.365.000 toneladas métricas (BODEN; MARLAND; ANDRES, 2010). Assim, caberia questionar, entre outras coisas, qual seria a capacidade de extração e de processamento do dióxido de carbono atmosférico por parte destas máquinas, quantas seriam necessárias e o que as movimentaria.

Diferentemente das máquinas acima citadas, há tecnologia que possibilite plantas industriais mais limpas e ambientalmente menos agressivas. O mesmo pode se dizer em relação à despoluição; um exemplo bastante ilustrativo é o rio Cheong Gye Cheon, na Coréia do Sul, que teve um trecho de quase $6 \mathrm{~km}$ de extensão despoluído e revitalizado. A obra foi concluída em 2005, e custou US\$386 milhões (REIS, 2010). Portanto, se ainda há indústrias poluidoras e rios contaminados, não é por limitações tecnológicas, mas sim econômicas.

É importante deixar claro que as objeções às opiniões fornecidas pelos jovens não pretendem, de modo algum, diminuí-los ou ridicularizá-los. Pelo contrário, a intenção é conduzir a análise e a discussão em consonância com os pressupostos fundamentadores desta pesquisa; para tanto, faz-se imprescindível a crítica que almeje a autonomia e a transformação. Não se trata, também, de buscar e apontar erros alheios; antes disso, prefere-se revelar incompletudes. Afinal somos todos seres em permanente construção (FREIRE, 1996).

Seguindo esse raciocínio, não se dirá que os jovens estão equivocados; mas, sim, que suas considerações estão incompletas. E dentro de um tema tão interdisciplinar como o ambiental, tais incompletudes afloram de forma bastante nítida, revelando os malefícios de um modelo educacional marcadamente disciplinar. 
Conforme citado anteriormente, dois dos ex-alunos entrevistados não souberam apontar medidas visando combater as mudanças climáticas; e ambos demonstram pessimismo em relação às perspectivas para as futuras gerações:

Segmento 13:

Al.1: Para mim falar a pura verdade eu acho que eles estão lascados ((risos)). Estão lascados porque não é de hoje que o povo, o povo para isso vê na televisão que passa que tem que conscientizar... vêm de uns 10 anos para cá já, e eu vejo que de uns 10 anos para cá o povo não mudou em nada. Disfarçou aqui, disfarçou ali mas continua a mesma coisa. Então falar a verdade eu nem paro para pensar daqui 50 anos. Eu faço, querendo ou não, eu faço a minha parte, mas a nossa parte não é suficiente. Então eu nem imagino.

Segmento 14:

Al.4: É porque é assim, hoje o mundo gira em torno do capital. Então... tudo gira em torno do dinheiro.

E.:Você acha que há possibilidade de mudar esta mentalidade, você é otimista em relação a isto, pessimista?

Al.4: Eu acho que não.

E.:Você acha que não muda...

Al.4: Não muda.

Os ex-alunos Al.1 e Al.4, portanto, não vislumbram a possibilidade de transformação da realidade vigente; essa concepção acaba por conduzir os indivíduos ao conformismo e à passividade. Ambos demonstram estar cientes da degradação ambiental em curso e dos riscos para a civilização; porém, agarrados ao bordão individualista estou faz̧endo a minha parte, deixam-se levar pelas circunstâncias, acreditando serem incapazes de interferir no meio social ao qual pertencem.

\subsection{Tema: Biodiversidade} responder:

Quando perguntados sobre o conceito de biodiversidade, apenas um dos jovens soube Segmento 15:

Al.5:Biodiversidade, ecossistemas, assim... é quantidade de plantas, (), biodiversidade... é a diversidade de animais () de plantas... ah, eu acho que a biodiversidade, assim, é a diversidade de espécies.

Embora a resposta esteja incompleta, Al.5 demonstrou ter um entendimento razoável a respeito do conceito e da importância da biodiversidade.

O desconhecimento do termo biodiversidade talvez seja o episódio mais emblemático do desinteresse da maioria dos ex-alunos em assuntos relacionados à temática ambiental. Há, porém, uma ressalva a ser feita; a jovem Al.3, - e apenas ela - ao término da entrevista, demonstrou curiosidade em saber o que era biodiversidade.

Não se pode pretender que todos os habitantes da Terra sejam profundos conhecedores das questões ambientais; e nem que se interessem pelo assunto. Porém, quando alguém afirma reconhecer que as ações humanas estão causando severos danos ambientais a ponto, inclusive, de colocar em risco o futuro da humanidade, seria aceitável esperar que este alguém demonstrasse preocupação com o futuro de seus filhos e netos. Sim, seria aceitável, mas ao mesmo tempo improvável, pois vive-se em um mundo imediatista e cheio de pressa.

\subsection{Projeto de Vida}

Objetivando aprofundar a discussão em torno das narrativas dos ex-alunos, há, ainda, algumas revelações colhidas durante as entrevistas de História de Vida que contribuem para a análise. Trata-se das considerações feitas pelos jovens quando indagados a respeito de seus sonhos, de seus projetos de vida: 
Al.2: Agora eu, o que eu planejo no futuro vou fazer um cursinho, né? Pretendo futuramente fazer uma faculdade... na área de farmácia mesmo que é uma área que eu gosto muito... por enquanto é só a faculdade e... ter minhas coisinhas, né? Conquistar minhas coisas...

E.: O que você pensa em conquistar...

Al.2: Conquista que eu posso dizer... pretendo ter minha casinha, já tenho o meu carro...

E.: O carro é seu...

Al.2: O carro é meu... ter minhas próprias coisas, andar com minhas próprias pernas, modo de dizer, ser um rapaz independente... financeiramente.

Segmento 17:

Al.1: Agora no mais eu acho que... estudar... crescer profissionalmente, ser mais independente do que já é, casar, ter sua casinha e nada demais.

Segmento 18:

Al.4: Assim, um sonho que eu consegui foi a casa própria, né? (...) Assim, agora, a gente tem, o nosso sonho é assim, a gente vai terminar de pagar e reformar no ano que vem, falta um ano para pagar, vai terminar de pagar e reformar. Vai fazer, aí, o que a gente quer, a gente quer deixar do nosso gosto, tudo bonitinho.

(...) O meu projeto de vida é viver bem. Eu e ele. Eu quero ter uma vida, assim, estável. Que dê para viver, ter a casinha, um carrinho na garagem, a moto, ele precisa da moto, eu também quero uma moto, tanto é que a gente está com plano de até o ano que vem eu tirar a carteira e já comprar uma moto. Mas, assim, por enquanto é só isso.

Segmento 19:

Al.3: (...) eu quero estudar mais, eu quero... agora voltei no que eu quero ser antes, ser professora de primeira à quarta série que eu adoro crianças... voltei lá atrás ((risos))... eu quero fazer magistério.

(...) Porque está precisando muito, a maioria dos professores estão querendo ser... para particular, não está tendo muito... muitos professores assim que se empenham mesmo na matéria. A gente vê que nem meu irmão mesmo... eu ensino mais ele aqui do que ele aprende na escola. Eu quero ser uma professora para ajudar mesmo. Por isso eu tenho vontade de aqui mesmo no... ainda mais que magistério aqui faz de graça no ( ). Eu tenho vontade quando ele tiver maiorzinho começar a fazer.

(...) Meu sonho é ter minha casa, bem arrumadinha, que nem eu moro na casinha dos meus pais, meu marido trabalha, não tem como eu trabalhar com criança pequena, mas assim que eu começar a trabalhar em quero construir minha casinha.

Segmento 20:

Al.5: É, meu sonho é Engenharia, quero fazer Engenharia Elétrica/Eletrônica.

O desejo mais comum dentro do grupo de jovens entrevistados é a conquista da casa própria; em seguida, vêm os estudos. No que tange a esse último, percebeu-se, ao longo das entrevistas, que a educação não possui uma mesma finalidade principal para todos.

Em relação aos diferentes papéis da educação na vida de cada entrevistado, foi possível estabelecer três diferentes categorias:

- Educação como promotora do conhecimento.

- Educação como incrementadora de renda.

- Educação como ação social.

Para Al.5 a educação é um caminho prazeroso que o leva a aprofundar seus conhecimentos na área escolhida; os desafios e as dificuldades enfrentadas nos estudos são estímulos na busca de seus objetivos:

Segmento 21:

Al.5: O curso que eu estou fazendo hoje já é um curso de tecnologia, superior também. É conta prá danar.

E.: Você pode repetir o nome do curso para mim?

Al.5: (...) Os meus amigos que entraram lá, eram 22, hoje tem quatro... comigo. Tirando alguns amigos meus que em semestre reprovaram em todas, tiraram zero em matéria. É nervoso lá.

Para Al.1, Al.2, e Al.4 a educação está mais relacionada à ascensão social: Segmento 22: 


\begin{abstract}
Al.4: Então, assim do nada, eu comecei a ver, entrar no site mesmo de faculdade, tudo, curso técnico para radiologia, falei assim, que, até eu achava que... será que é mexer com rádio isso? Aí, entrei lá, não, é técnico em raio $\mathrm{X}$, falei assim, olha que profissão boa. Você vai ficar atrás de uma salinha apertando um botãozinho, tirando raio X. E ganha bem, é uma área que ganha bem. Falei assim, não, esta é a profissão que eu quero.
\end{abstract}

As narrativas sugerem que, para alguns dos alunos entrevistados, a educação é apenas um meio para se atingir um fim maior: o aumento de renda. Sob essa ótica, a escola torna-se, então, uma instituição voltada principalmente para a capacitação de pessoas para o mercado de trabalho (PAOLI, 1981).

$\mathrm{Na}$ prática, é comum observar escolas do ensino médio - em especial as privadas empenhando-se em divulgar seus elevados índices de aprovação no vestibular; no ensino superior, universidades - principalmente as particulares - capricham nas imagens de jovens recém-formados exercendo prestigiadas e bem remuneradas profissões.

Tal sistema de ensino, rigidamente formatado para atender às demandas mercadológicas, é fortemente influenciado por interesses políticos e econômicos voltados para a manutenção do status quo de uma minoria (BRANDÃO, 2007).

Mesmo aqueles que buscam a educação movidos pela ânsia de novos conhecimentos acabam, muitas vezes, tolhidos pelo excessivo foco no mercado e pelo formato predominantemente disciplinar presente em muitas instituições de ensino. Nas aspirações educacionais desses jovens, ainda que sutilmente, a escola emerge ora como uma instituição de conveniência, ora como uma instituição fragmentadora do saber.

Almejar a casa própria, como fazem os jovens entrevistados, não é nenhum absurdo; absurdo, sim, é ter que cercar o imóvel com altos muros encimados de cercas elétricas e câmeras de vigilância. Mas o disparate torna-se ainda mais gigantesco quando todas essas medidas de segurança são encaradas como normais. Ser bem sucedido não é, de forma alguma, um defeito. Porém, deve estar defeituosa uma sociedade onde o sucesso é alcançado por bem poucos.

Individualismo exacerbado, competição ferrenha e insensibilidade são, todos, efeitos colaterais da racionalidade econômica que envolve e manipula as pessoas. Socialmente, o mundo continua injusto; ambientalmente, por força do homem, o mundo está se tornando cada vez menos habitável.

Merece, porém, uma análise diferenciada a narrativa de Al.3 constante do segmento 19. Esta ex-aluna, que queria cursar Direito quando era adolescente, volta-se agora para o magistério. Suas razões fundamentam-se no apego pelas crianças e no desejo de atuar em uma profissão cuja procura está em declínio, devido principalmente aos baixos salários e às más condições de trabalho ${ }^{4}$ Al.3, portanto, não embasa sua decisão profissional na remuneração ou em alguma vaidade intelectual ou mesmo na absoluta falta de opção; a decisão de Al.3 apoia-se na solidariedade.

Esse pequeno gesto anônimo de Al.3 traz embutido alguns significados importantes; em primeiro lugar, ele demonstra que o agir humano não cabe em um molde. Portanto, a imagem pretensamente generalista - de que somos criaturas egoístas, destruidoras e incorrigíveis não se sustenta diante da complexidade e da diversidade humanas.

Em segundo lugar, há um paradoxo embutido na fala de Al.3; ao mesmo tempo em que se declara pessimista em relação ao futuro, ela também - e sem aperceber-se disso - dá um testemunho de esperança e de crença na posteridade ao fazer sua escolha profissional. Se a narrativa de Al.3 pode, eventualmente, ser contraditória, também o é a sociedade humana e as instituições que a sustentam.

\footnotetext{
4 Amaral e Oliveira (2011), citando os dados do Censo do Ensino Superior do MEC, informam que entre os anos de 2005 e 2009 o número de graduados em Pedagogia e Normal Superior reduziu-se de 105 mil para 52 mil. Fonte: http://www.scielo.br/pdf/ensaio/v19n73/08.pdf p. 883. Acesso em 03/10/2012.
} 
Por fim, se há pessoas comuns contrariando algumas tendências e ignorando certos padrões comportamentais, seria razoável supor que ações meramente adaptativas podem, gradativamente, ceder espaço a ações transformadoras.

\section{Considerações Finais}

O ponto comum em relação aos jovens entrevistados estava no fato de todos terem participado de atividades dentro do Programa Agrinho; ou seja, todos tiveram contato, quando crianças, com um programa de educação ambiental. Convém salientar, no entanto, que para a maioria desses ex-alunos a participação teve duração de apenas algumas semanas, tempo necessário para se trabalhar e redigir um texto; concluída essa tarefa, encerravam-se as atividades com o Agrinho. Esses jovens declararam, ainda, que não voltaram a ter contato com o programa ao longo da vida estudantil. O ex-aluno que atuou na categoria Experiência Pedagógica participou de atividades que se estenderam ao longo de todo ano letivo; porém, como os demais, não voltou a ter contato com o programa posteriormente. Essa curta vivência - além de explicar a pouca lembrança que revelaram ter do Agrinho - denuncia um contato descontinuado e superficial com os materiais do programa.

Ao longo de todas as entrevistas, buscou-se identificar a emergência espontânea de qualquer assunto relacionado à temática ambiental, fato que não ocorreu com nenhum dos exalunos. Em um segundo momento, os jovens foram questionados a respeito de temas ambientais recorrentes nos materiais do Agrinho (Água, Clima e Biodiversidade).

As respostas obtidas possibilitaram concluir que as questões ambientais não se encontram no rol das prioridades na vida desses ex-alunos. Os conhecimentos demonstrados revelaram-se exíguos para os temas Água, Clima e Biodiversidade; e, nesse ponto, emerge um intrigante paradoxo.

Embora não tenham demonstrado significativo interesse ou preocupação com os temas, todos os jovens, sem exceção, atribuíram a responsabilidade pelos danos ambientais às ações do ser humano. E quase todos eles enxergam na destruição do meio ambiente um fator de risco para o futuro da humanidade.

Certamente, pode haver muitas explicações para uma atitude de tamanha passividade diante de uma ameaça de tal magnitude; porém, dentro dos limites desta pesquisa, podem-se apontar algumas possíveis razões.

A primeira delas está no individualismo que tomou conta de nossa sociedade; assim, os problemas parecem estar sempre nos outros uma vez que eu estou fazendo a minha parte. Os jovens parecem desconhecer que somente a ação conjunta, politizada e democrática pode acarretar mudanças significativas em nossa sociedade.

A segunda razão é o sentimento de impotência perante um mundo que não tem mais jeito; o indivíduo, portanto, não se vê como alguém que pode intervir para transformar a realidade.

Uma terceira razão está em uma visão de mundo fragmentada, muito influenciada por um sistema educacional onde as disciplinas são compartimentalizadas. As pessoas, então, não conseguem formar um número de conexões que lhes permita enxergar uma situação problema de forma mais clara e abrangente.

As narrativas dos ex-alunos revelaram, ainda, a predominância de uma visão de educação voltada principalmente para o aumento da renda. A educação, portanto, atua também como cúmplice de um sistema econômico que constrói valores e determina comportamentos sociais. Mas, ao mesmo tempo em que é submissa, a educação pode ser também libertadora de homens e mentes; e ao mesmo tempo em que segrega e justifica as desigualdades, a educação é, também, instrumento essencial para a promoção da solidariedade e da justiça social. Essa ambiguidade parece ter ficado bastante evidenciada na narrativa de uma das ex-alunas; para Al.3, a educação é, antes de tudo, um caminho para a construção de um mundo melhor. 


\section{Referências}

AMARAL, D. P. do.; OLIVEIRA, F. B. de. O Prouni e a conclusão do ensino superior: novas trajetórias pessoais e profissionais dos egressos. Ensaio: aval. pol. públ. Educ., Rio de Janeiro, v. 19, n. 73, p. 861-890, out./dez. 2011.

BRASIL. Casa Civil. Lei n. 8315, de 23 de dezembro de 1991. Cria o Serviço Nacional de Aprendizagem Rural (Senar). Disponível em: <http://www.planalto.gov.br/ccivil_03/leis/L8315.htm>. Acesso em: 14 out. 2011.

BRASIL. Casa Civil. Decreto n. 566 de 10 de junho de 1992. Regulamenta o Serviço Nacional de Aprendizagem Rural (Senar). Disponível em: <http://www.planalto.gov.br/ccivil_03/decreto/19901994/D0566.htm >.Acesso em: 14 out. 2011.

BODEN, T. A.; MARLAND, G.; ANDRES, R. J. Global, regional and national fossil-fuel CO2 emissions. U.S. Department of Energy, Oak Ridge, Tenn., USA, 2010. Disponível em:

<http://cdiac.ornl.gov/trends/emis/tre_glob.html>. Acesso em: 10 set. 2012.

BOGDAN, R. C.; BIKLEN, S. K. Investigação qualitativa em educação. Porto: Porto Editora, 1994.

BRANDÃO, C. R. O que é educação. São Paulo: Brasiliense, 2007.

CONFEDERAÇÃO NACIONAL DA INDÚSTRIA (CNI). Matriz energética: cenários, oportunidades e desafios. Brasília: CNI, 2007.

DIAMOND, J. M. Colapso: como as sociedades escolhem o fracasso ou o sucesso. Rio de Janeiro: Record, 2005.

FREIRE, P. Pedagogia do oprimido. Rio de Janeiro: Paz e Terra, 2005.

FREIRE, P. Educação como prática da liberdade. Rio de Janeiro: Paz e Terra, 2003.

FREIRE, P. Pedagogia da autonomia: saberes necessários à prática educativa. São Paulo: Paz e Terra, 1996.

GIL, A. C. Métodos e técnicas de pesquisa social. Ged. São Paulo: Atlas, 2008.

GOMES, R. A análise de dados em pesquisa qualitativa. In: MINAYO, M. C. de S. (Org.). Pesquisa social: teoria, método e criatividade. 11ed. Petrópolis: Vozes, 1994. p.67-75.

INSTITUTO BRASILERO DE GEOGRAFIA E ESTATÍSTICA (IBGE). Pesquisa nacional de saneamento básico 2008. Rio de Janeiro, 2010. Disponível

em: <http://www.ibge.gov.br/home/estatistica/populacao/condicaodevida/pnsb2008/PNSB_2008.pdf $>$. Acesso em: 05 out. 2012.

JACOBI, P. R. Educação ambiental: o desafio da construção de um pensamento crítico, complexo e reflexivo. Educação e Pesquisa, São Paulo, v.31, n.2, p.233-250, maio/ago. 2005.

JONAS, H. O princípio responsabilidade: ensaio de uma ética para a civilização tecnológica. Rio de Janeiro: Contraponto, 2006.

LEFF, E. Racionalidade ambiental: a reapropriação social da natureza. Rio de Janeiro: Civilização Brasileira, 2006.

LOUREIRO, C. F. B. Trajetórias e fundamentos da educação ambiental. 3ed. São Paulo: Cortez, 2009. 
MARCONI, M. de A.; LAKATOS, E. M. Técnicas de pesquisa: planejamento e execução de pesquisas, amostragens e técnicas de pesquisa, elaboração, análise e interpretação de dados. 7ed. São Paulo: Atlas, 2008.

MARÍN, J. Globalização, diversidade cultural e desafios para a educação. Revista de Educação Pública, Cuiabá, v.16, n.30, p.139-160, jan./abr. 2007.

MARTINS, G. de A.; THEÓPHILO, C. R. Metodologia da investigação cientifica para ciências sociais aplicadas. São Paulo: Atlas, 2007.

MINAYO, M. C. S.; SANCHES, O. Quantitativo-Qualitativo: oposição ou complementaridade? Cad. Saúde Públ., Rio de Janeiro, v.9, n.3, p.239-262, jul/set, 1993.

PAOLI, N. J. Ideologia e hegemonia: as condições de produção da educação. São Paulo: Cortez/Autores Associados, 1981.

PAULILO, M. A. S. A pesquisa qualitativa e a história de vida. Revista Serviço Social, Londrina,v.2, n.2, p.135-148, jul./dez. 1999.

QUINTAS, J.S. Educação no processo de gestão ambiental pública: a construção do ato pedagógico. In: LOUREIRO, C. F. B.; LAYRARGUES, P. P.; CASTRO, R. S. de (Orgs.). Repensar a educação ambiental: um olhar crítico. São Paulo: Cortez, 2009. p.33-79.

REIS, V. L. Desenbo urbano ambiental: bases projetuais para o aumento de área permeável no centro de Curitiba-PR. 2010. Monografia (Curso de Arquitetura e Urbanismo) - Universidade Federal do Paraná, Curitiba, 2010. Disponível em: <http://pt.scribd.com/doc/70441073/Monografia-VivianeReis-2010>. Acesso em: 05 out. 2012.

SAUVÉ, L. Educação ambiental: possibilidades e limitações. Educação e Pesquisa, São Paulo, v.31, n.2, p.317-322, maio/ago. 2005.

TORRES, P. L. A trama do conhecimento. In: (Org.). Alguns fios para entretecer o pensar e o agir. Curitiba: SENAR-PR, 2007. p.7-24.

TORRES, P. L.; CERVI, R. de M. Programa Agrinho: uma história de resultados, 1996/1999. Curitiba: SENAR-PR, 2001. 